\title{
Surgical Treatment of Ulcers: Current and Future Practices
}

\section{Dennis Adjepong, MD, MBA ${ }^{1} \mathbb{D}$, Dennis Brako Sarpong, MD, MHA $^{2}$, Naa Oyoo Shidaa Korney, MD, MHA ${ }^{2}$, Anna Amoako- Kankam, $\mathrm{MD}^{3}$ and Kwaku Amoateng ${ }^{4}$}

${ }^{1}$ Department of Neurological Surgery, California Institute of Behavioral Neurosciences \& Psychology, Fairfield, USA

${ }^{2}$ Washington Adventist University, Takoma Park, USA

${ }^{3} 37$ Military Hospital, Accra, Ghana

${ }^{4}$ University of Medicine \&Pharmacy of Targus Mures, Transylvania, Romania

\begin{abstract}
CPressure sores occur mainly from any prolonged pressure, friction or shear forces on the skin surface. The article reviews the causes, severity, diagnosis, prevention, and surgical management of the disease. In this study, more focus was placed on the genetics, biochemistry, and pathophysiology of the disease. Special attention was directed at the current modalities of treatment of different stages of pressure ulcers. Prevention is by far the easiest method to contain this disease, but only when detection is done early enough. They are familiar with those who have been bedridden for quite some time, immobile, and those on wheelchairs. The extent of the severity determines the level of management it will need. Surgical intervention is generally recommended for patients with stages 3 and 4 of deep pressure ulcers, which are often caused by injuries to the spinal cord. Current treatment options include reconstructive surgery, which involves debriding the wound before adding new tissue into it. Future trends affecting wound therapy, along with their advantages and disadvantages, have also been discussed.
\end{abstract}

Keywords: Pressure ulcer; Recurrent ulcer

\section{Introduction}

Pressure ulcers, also known as bedsores or decubitus ulcers, are caused by continuous pressure that distorts and breaks down

*Corresponding author: Dennis Adjepong, Department of Neurological Surgery, California Institute of Behavioral Neurosciences \& Psychology, Fairfield, USA, Tel: +1 5712771998; E-mail: adjepongdennis1@gmail.com

Citation: Adjepong D, Sarpong DB, Korney NOS, Amoako-Kankam A, Amoateng K (2020) Surgical Treatment of Ulcers: Current and Future Practices. J Surg Curr Trend Innov 4: 046.

Received: August 18, 2020; Accepted: September 04, 2020; Published: September 11, 2020

Copyright: (c) 2020 Adjepong D, et al. This is an open-access article distributed under the terms of the Creative Commons Attribution License, which permits unrestricted use, distribution, and reproduction in any medium, provided the original author and source are credited. the underlying skin tissue [1]. This kind of stress results in tissue ischemia, inadequate oxygen and nutrition supply, and ultimately tissue necrosis [2]. Most of the time, a pressure ulcer is a potentially critical condition requiring immediate treatment [3]. The options of either conservative or surgical treatment are dependent on the ulcer stage [4]. Surgical candidates are usually those with spinal cord injuries and often require extensive surgery to ensure recurrence doesn't happen [5]. The famous sites that are prone to pressure ulcers include heels, back of the arms, shoulder blades, lower back, and the hip [6]. The paper analyzes the results of the treatment plan for a group of patients with decubitus operated between 2016 and 2018 [7].

\section{Methods}

The group of 50 patients was all diagnosed with stages III or IV of 68 pressure sores, mostly in the pelvic region, requiting immediate surgeries [2]. The medical research and procedures were undertaken at Mayo Clinic in Minnesota [8]. Thirty-eight males and 12 females with an age range of between 19 to 65 underwent surgery [9]. There were 34 pressure sores in the sacral region, 9 in the trochanteric, and 25 occurred in the ischial area (Table 1).

\begin{tabular}{|c|c|c|c|}
\hline Region & No. of pressure ulcers & Sex (M/F) & No. of complications \\
\hline Sacral & 34 & $29 / 5$ & 6 \\
\hline Trochanteric & 9 & $7 / 2$ & 1 \\
\hline Ischial & 25 & $15 / 10$ & 9 \\
\hline Total & 68 & & $16(23.5 \%)$ \\
\hline
\end{tabular}

Table 1: Pressure ulcers data.

Thirty patients had only one infected region, 11 had two areas, four patients had ulcers in three regions, and one male had decubitus in four regions [10]. It was also noted that some of the patients with multiple pressure ulcers received reconstructive surgeries at different stages as per the developing sores, which occurred at various times as well [11]. Dressing of the sacral wounds was done using single or double gluteus maximum flaps [12]. Those with ischial ulcers were covered with either biceps femoris or gluteus maximum hatchet flaps [13]. Questionnaires with instructions and contact details were issued to the patients for assessment of the surgical treatment received [14].

\section{Results}

Despite the $23.5 \%$ complication rate of the 68 operated cases, all patients were successfully discharged after a six-week stay in the hospital [2]. All options, such as skin grafting, local flaps, and direct closure, were utilized per the patient's compliance and acceptable surgical procedures [15]. The general conditions of the patients were keenly observed, and no cases of deterioration were reported [16]. However, two females in their early 60s exhibited post-surgical complications but were promptly treated, and the situation neutralized [17]. From the 50 issued questionnaires, 45 were received [18]. Out of these, the number of accurately completed questions was 38 [12]. 
These were later included in the review section of the facility's website [2]. From the questionnaire replies, no recurrences were recorded [19]. However, on further assessment eight months after the treatment procedure, two among the five patients that failed to return feedback had recurrences [20]. They refused new treatment owing to the high costs involved but, most importantly, their advancing age [21]. The medical research team later found out that the patients in question had pre-existing spinal cord injuries before being treated [22].

\section{Discussion}

Ever since their introduction in 1993, skin flaps have been successfully used, especially during the dressing of the sacral pressure sores [23]. Currently, the musculocutaneous and fasciacutaneous flaps are commonly used for surgical operations [24]. With time, however, there have been unconventional and advanced treatment protocols, such as the use of sensate flaps [25]. These flaps have sensory nerves intact and have been used to treat spinal cord sores mainly by protecting the already anesthetized region [26]. With sensate flaps, the chances of recurrence are reduced to almost nil despite the unpleasant feeling the patient might undergo [4]. From the study, the frequent intense and extensive medical research carried out by Mayo's medical team ensured success in the surgical procedures [19]. All patients were found to be cooperative in both the pre- and post-treatment procedures [7]. The physician's sole objectives were to oversee efficient debridement, stoppage of inflammation or sore discharge, removal of dead tissue, covering up any exposed bones, and closing of the defect with skin replacements [6]. The majority of the patient's health conditions significantly improved as a result, save for the two who had recurrences [27].

\section{Pathophysiology of Pressure Ulcers}

Pressure ulcers are among the most prevalent dermatologic disorders affecting the American population, with over 2 million infected persons treated annually [9]. Persons with Spinal Cord Injuries (SCI) and the disabled such as those with paraplegia or quadriplegia, are more likely to be infected [14]. The main factors that contribute to occurrences of ulcer wounds are pressure, friction, shearing force, and moisture [7]. When soft tissues are pressed against external surfaces for long periods, they develop tissue ischemia, and micro-vascular occlusion also occurs, leading to hypoxia [18]. On friction, when one rubs his/her skin against bedding or clothing, skin ulceration occurs, which leads to erosion where the epidermis and superficial dermis layers are destroyed [23]. Shearing forces are indirect factors that trigger pressure sores, and they occur when one is in an inclined position or surface [5]. It's caused by two entities move in separate directions like the tailbone moving down when one slides on an elevated bed [8]. Moisture, such as sweat, causes maceration and breakdown of tissues hence triggering or complicating pressure sores [28].

\section{Biochemistry of Pressure Ulcers}

Efficient hydration and nutrition play a crucial role in the treatment of pressure ulcers injuries. Wounds naturally heal following the rate of food and fluid intake [2]. A poor diet would nonetheless hamper the healing process for the damaged tissue [18]. Multiple research, including The National Pressure Ulcer Long-term Care Study, has proved that having a weak diet and frequent weight loss are the major risk factors for developing pressure sores [22]. Wounds in pressure ulcers are chronic and immune to the normal iterative healing process, thanks to the presence of high bioburden [28]. In the pressure wound metabolic environment, there exists a dominant presence of Firmicutes, Proteobacteria, and Actinobacteria [13]. The colonization of the wound by these multiple pathogens, however, differs from one sore to another [29]. Consequently, more research is still being done on the association between the metabolic wound environment and the colonizing bacteria present, which could prove essential in exploiting new prognostic or therapeutic interventions [27].

\section{Extensive, multiple \& recurrent pressure ulcers}

There are four stages of recurrent pressure ulcers [12]. In stage 1, the affected area of the skin is intact and appears discolored, i.e., red in whites and purple or blue in dark-colored people [23]. In stage 2, some part of the epidermis and dermis is damaged leading to skin loss [19]. It looks like an open blister or wound [16].

In stage 3 , the underlying skin tissue is fully damaged, but the underlying bone and muscle are not damaged [2]. The pressure ulcer now appears as a deep cavity-like wound [1]. In stage 4, the skin is severely damaged and leading to the death of the surrounding tissue [20]. The underlying bone, joint, or muscles may also be exposed [15].

\section{Pressure ulcers debridement}

Debridement is needed when a pressure ulcer is healing at a slower rate [9]. The presence of devitalized, necrotic tissue supports the formation of pathologic organisms that prevents healing [1]. Debridement i.e., removal of the dead tissue from a wound is applied to aid pressure ulcer healing [30]. The necrotic tissue can be removed by autolytic debridement by the aid of moist wound dressing during natural wound healing [3].

There are four types of debridement methods: enzymatic, mechanical, sharp, and autolytic [21]. The factors to consider when selecting a method include the patient's health condition, presence or absence of infection, the ulcer presentation, skill set of the practitioner, and patient's ability to endure the procedure [28].

\section{Pressure ulcer resistant to healing: what factors accounts for the trend in surgical management?}

Most of the diabetic non-healing ulcers are a symptom of PAD [3]. These symptoms include chronic wounds, non-healing sores on the feet, pain and fatigue on the legs, and difficulty in moving [30].

Immune-suppressed patients are likely to experience a challenging time given that their immunity gets compromised [6]. The wound becomes aggressively progressive; with patients likely to go through traumatizing experiences due to their unresponsiveness to standard treatments [15].

Most of the wounds are this time are infected by bacteria, either originating from the skin or normal flora [16]. Research has showed that most of the bacteria causing infections include staphylococci, staphylococcus, among others from the outer environment [2].

The wound healing process depends on the individual's body's response [23]. Immuno-suppressed patients have increased risk for hypothermia, thus affecting the postoperative wound healing process and increase the risk of infection [13]. Diabetic patients have high 
levels of blood glucose that affect the nerves leading to poor blood circulation thus less blood needed for skin repair or to reach the affected areas [16].

Primary wound healing involves cleaning a wound without tissue loss [7]. The edges of the wound are brought together by the use of sutures, adhesive tape, staples, or glue [16]. Secondary wound healing occurs when the sides of the sore are not exposed thus it occurs from the bottom of the wound upwards [20].

\section{Treatment options for all stages of pressure ulcers}

Stage 1 and 2 PrUs can be treated by removing pressure on the affected area and keep the area clean and dry to prevent further tissue damage [6]. Stages 3 and 4 PrUs can be treated by proper debriding and dressing the wound cavity, create moisture for optimal healing to protect the wound from infection [26].

Proper hydration and nutrition support a faster wound healing process [12]. Nutrients such as Zinc, protein, calcium, and Vitamins A, C, and E can facilitate a faster-wound healing process. Negative pressure wound therapy involves attachment of a suction tube that draws moisture from the ulcer, hence reducing infection risk and healing time [11]

\section{Genetics of pressure ulcers}

For pressure sores occurrence, anyone who is confined to a chair or a bed for prolonged periods is susceptible to infection [30]. As noted from the study carried above, most of the patients led lifestyles with poor choices, including little to nil exercising coupled with poor diet plans. Pressure ulcers are not hereditary and are only caused by the stated risk factors [3].

\section{Scientific Analysis}

The feedback received showed that rigorous assessments are crucial before issuing treatment protocols to pressure ulcer patients [13]. The testing should be able to force the causative agent to be removed before implementing management plans such as improved nutrition [2]. The other reason why there were no recurrence incidences is due to the quality and advanced post-operative patient care the facility offered [3]. Some patients were even recorded to have assumed a supine posture as early as two weeks post-surgery [19].

\section{The Clinical Analysis}

Before being operated on, all patients' wounds had to adequately prepared and inspected by the physicians [1]. This is a crucial stage since any mistake or overlooked development may result in a postsurgical complication and ultimately lead to a recurrence [11]. Patient compliance also proved to be a critical aspect as lack of it meant compromising the surgery results [7]. A lot of emphases were mainly placed on the debridement protocol, which involved removing the dead tissue and any contaminated surface on the wound [21]. Some female patients with multiple sores, for instance, had mechanical debridement procedures such as ultrasounds, lasers, and pressure irrigation [12]. These techniques employed the use of low-frequency energy, light beams, and powerful bursts of water, respectively [5]. New trends that have been subjects of interest recently include the negative-pressure wound therapy where tissues are healed in a given vacuum, getting rid of inflammations in the process [3]. Specialists of plastic surgery have also been involved in the treatment of pressure ulcers through the application of pedicled flaps [10]. Failure to treat pressure ulcers increase the risk of developing a malignant cancerlike ulcer called Marjolin's cancer [23].

\section{The Unanswered Questions}

Will the average patient be able to afford future advanced treatment options [29]? Will ulcer recurrence be forever eliminated by the new trends, and how will that be achieved at an affordable rate [16]? How will a typical clinic budget favor with purchase and maintenance of such equipment [27]? And most importantly, will the new technology value the patient's decisions [9]? These are vital aspects that need to be addressed by physicians involved in the respective researches [28]. Patients and medical facilities will need to find common ground to manage the disease efficiently [18].

\section{Conclusion}

After a successful study at a very renowned facility, a significant discovery was made.More research was needed towards ensuring a more extensive patient selection with improved compliance. More skilled surgeons and highly advanced equipment that can incorporate future trends were also identified as critical aspects to the median attaining great results. With such directives, the recurrence rate would highly be nil if future concepts such as the use of robotics and other electrical forms of stimulation in SCI patients are adopted. Those with SCI can also develop severe complications that are impossible to treat, socially uncomfortable, and recurring. Plastic surgery, which continues to be a booming business in the medical world, should be further exploited by physicians in a way that can benefit patients with pressure sores. Not forgetting the economic burden that pressure ulcers bring upon the affected family, practical and affordable management plans need to be drafted soon to contain it.

\section{References}

1. Kwok AC, Simpson AM, Willcockson J, Donato DP, Goodwin IA, et al. (2018) Complications and their associations following the surgical repair of pressure ulcers. Am J Surg 216: 1177-1181.

2. Cervantes-García E, Salazar-Schettino PM (2017) Clinical and surgical characteristics of infected diabetic foot ulcers in a tertiary hospital of Mexico. Diabetic foot \& ankle 8: 1367210.

3. Gurusamy KS, Pallari E (2016) Medical versus surgical treatment for refractory or recurrent peptic ulcer. Cochrane Database of Syst Rev 3: CD011523.

4. Kreutzträger M, Voss H, Scheel-Sailer A, Liebscher T (2018) Outcome analyses of a multimodal treatment approach for deep pressure ulcers in spinal cord injuries: a retrospective cohort study. Spinal cord 56: 582-590.

5. La Fontaine J, Crisologo PA, Lavery L (2019) Current Concepts in Curative surgery for diabetic forefoot ulcers. The Foot 39: 37-44.

6. Tsuchiya I, Kato Y, Tanida E, Masui Y, Kato S, et al. (2017) Effect of vonoprazan on the treatment of artificial gastric ulcers after endoscopic submucosal dissection: Prospective randomized controlled trial. Digestive Endoscopy 29: 576-583.

7. Bielecki M, Bielecki P, Żebrowski P, Misiak B, Lewko J (2018) Operative treatment of pressure ulcers using pedicled flaps. Prog Health Sci 8: 105111. 
8. Milcheski DA, Mendes RR, Freitas FR, Zaninetti G, Moneiro AA Júnior, et al. (2017) Brief hospitalization protocol for pressure ulcer surgical treatment: outpatient care and one-stage reconstruction. Rev Col Bras Cir 44: 574-581.

9. Altieri MS, Pryor A, Yang J, Yin D, Docimo S, et al. (2018) The natural history of perforated marginal ulcers after gastric bypass surgery. Surgical endoscopy 32: 1215-1222.

10. Michailidis L, Bergin SM, Haines TP, Williams CM (2018) Healing rates in diabetes-related foot ulcers using low frequency ultrasonic debridement versus non-surgical sharps debridement: a randomised controlled trial. $\mathrm{BMC}$ research notes 11: 1-5.

11. Seren M, Dumantepe M, Fazliogullari O, Kucukaksu S (2017) Combined treatment with endovenous laser ablation and compression therapy of incompetent perforating veins for treatment of recalcitrant venous ulcers. Phlebology 32: 307-315.

12. Busch C, Aschermann I, Mnich CD (2017) Treatment of chronic ulcers. Phlebologie 46: 13-18

13. Kasparova EA, Sobkova OI, Fedorov AA, Kasparov AA (2017) Surgica treatment of purulent corneal ulcers in eyes with neurotrophic keratitis and paralytic lagophthalmos. Vestn Oftalmol 133: 32-37.

14. Smith PDC (2017) Drug treatment of varicose veins, venous edema, and ulcers. Handbook of Venous and Lymphatic Disorders: Guidelines of the American Venous Forum, $\left(4^{\text {th }}\right.$ edn. $)$. CRC Press, Florida, USA.

15. Tao F, Tang X, Tao H, Luo Y, Cao H, et al. (2020) Surgical treatment of diabetic foot ulcers during the COVID-19 pandemic in China. J Diabetes Complication. 14: 107622

16. Finestone AS, Tamir E, Ron G, Wiser I, Agar G (2018) Surgical offloading procedures for diabetic foot ulcers compared to best non-surgical treatment: a study protocol for a randomized controlled trial. J Foot Ankle Res 11: 6 .

17. Bamba R, Madden JJ, Hoffman AN, Kim JS, Thayer WP, et al. (2017) Flap reconstruction for pressure ulcers: an outcomes analysis. Plast Reconstr Surg Glob Open 5: 1187.

18. Fusaro F, Tambucci R, Romeo E, Bagolan P, Dall'Oglio L, et al. (2018) Anastomotic ulcers in short bowel syndrome: New suggestions from a multidisciplinary approach. Journal of pediatric surgery 53: 483-488.

19. Patel T, Wimmers EG, Pontell M, Saad A (2017) Surgical Reconstruction of Pressure Ulcers. Rehabilitative Surgery Pg No: 157-178.
20. Bettex Q, Philandrianos C, Jaloux C, Bertrand B, Casanova D (2019) Surgical treatment of recurrent pressure ulcers in spinal cord injured patients. Ann Chir Plast Esthet 64: 674-684.

21. Ahmed MR, Rajadas J, Ahmed MIN, Sun W, Nicolls MR (2019) Elafin Incorporated Biomaterials for the Treatment of Chronic Tissue Ulcers. Justia Patents, California, USA.

22. Marina CN, Danciu R, Raducu L, Scaunasu RV, Jecan CR, et al. (2019) The surgical treatment of diabetic foot ulcers. J Clin Invest Surg 4: 96-100.

23. Wysong A, Taylor BR, Graves M, Mishra V, Gilbertson R, et al. (2016) Successful treatment of chronic venous ulcers with a 1,320-nm endovenous laser combined with other minimally invasive venous procedures. Dermatologic Surgery 42: 961-966.

24. Bosanquet DC, Wright AM, White RD, Williams IM (2016) A review of the surgical management of heel pressure ulcers in the 21 st century. Int Wound J 13: 9-16.

25. Pehde CE, Bennett J, Kingston M (2020) Orthoplastic Approach for Surgical Treatment of Diabetic Foot Ulcers. Clinics in Podiatric Medicine and Surgery $37: 215-230$.

26. Marangi GF, Pallara T, Lamberti D, Perrella E, Serra R, et al. (2018) An electrical plasma dissection tool for surgical treatment of chronic ulcers Results of a prospective randomised trial. International wound journal 15 : 717-721.

27. Han HH, Choi EJ, Choi JY, Rhie JW (2016) Efficacy of one-stage surgica treatment and clinical features in patients with multiple pressure ulcers. International Wound Journal 13: 7-12.

28. Kim YH, Kim H, Cheon JH, Kang DH (2019) Epinephrine Infiltration and the Incidence of Bleeding Complications after Surgical Debridement of Pressure Ulcers with Negative Pressure Wound Therapy. Journal of Wound Management and Research 15: 85-90.

29. Alavi A, Sibbald RG, Phillips TJ, Miller OF, Margolis DJ, et al. (2016) What's new: Management of venous leg ulcers: Treating venous leg ulcers. J Am Acad Dermatol 74: 643-664.

30. Jianguo LI, Fang HU, Xie M (2017) Impact of adherence of pus moss on the efficacy of different surgical procedures for perforated peptic ulcers. The Journal of Practical Medicine 33: 2355-2358. 


\section{di \\ нетан}

Advances In Industrial Biotechnology | ISSN: 2639-5665

Advances In Microbiology Research | ISSN: 2689-694X

Archives Of Surgery And Surgical Education | ISSN: 2689-3126

Archives Of Urology

Archives Of Zoological Studies | ISSN: 2640-7779

Current Trends Medical And Biological Engineering

International Journal Of Case Reports And Therapeutic Studies | ISSN: 2689-310X

Journal Of Addiction \& Addictive Disorders | ISSN: 2578-7276

Journal Of Agronomy \& Agricultural Science | ISSN: 2689-8292

Journal Of AIDS Clinical Research \& STDs | ISSN: 2572-7370

Journal Of Alcoholism Drug Abuse \& Substance Dependence | ISSN: 2572-9594

Journal Of Allergy Disorders \& Therapy | ISSN: 2470-749X

Journal Of Alternative Complementary \& Integrative Medicine | ISSN: 2470-7562

Journal Of Alzheimers \& Neurodegenerative Diseases | ISSN: 2572-9608

Journal Of Anesthesia \& Clinical Care | ISSN: 2378-8879

Journal Of Angiology \& Vascular Surgery | ISSN: 2572-7397

Journal Of Animal Research \& Veterinary Science | ISSN: 2639-3751

Journal Of Aquaculture \& Fisheries | ISSN: 2576-5523

Journal Of Atmospheric \& Earth Sciences | ISSN: 2689-8780

Journal Of Biotech Research \& Biochemistry

Journal Of Brain \& Neuroscience Research

Journal Of Cancer Biology \& Treatment | ISSN: 2470-7546

Journal Of Cardiology Study \& Research | ISSN: 2640-768X

Journal Of Cell Biology \& Cell Metabolism | ISSN: 2381-1943

Journal Of Clinical Dermatology \& Therapy | ISSN: 2378-8771

Journal Of Clinical Immunology \& Immunotherapy | ISSN: 2378-8844

Journal Of Clinical Studies \& Medical Case Reports | ISSN: 2378-8801

Journal Of Community Medicine \& Public Health Care | ISSN: 2381-1978

Journal Of Cytology \& Tissue Biology | ISSN: 2378-9107

Journal Of Dairy Research \& Technology | ISSN: 2688-9315

Journal Of Dentistry Oral Health \& Cosmesis | ISSN: 2473-6783

Journal Of Diabetes \& Metabolic Disorders | ISSN: 2381-201X

Journal Of Emergency Medicine Trauma \& Surgical Care | ISSN: 2378-8798

Journal Of Environmental Science Current Research | ISSN: 2643-5020

Journal Of Food Science \& Nutrition | ISSN: 2470-1076

Journal Of Forensic Legal \& Investigative Sciences | ISSN: 2473-733X

Journal Of Gastroenterology \& Hepatology Research | ISSN: 2574-2566
Journal Of Genetics \& Genomic Sciences | ISSN: 2574-2485

Journal Of Gerontology \& Geriatric Medicine | ISSN: 2381-8662

Journal Of Hematology Blood Transfusion \& Disorders | ISSN: 2572-2999

Journal Of Hospice \& Palliative Medical Care

Journal Of Human Endocrinology | ISSN: 2572-9640

Journal Of Infectious \& Non Infectious Diseases | ISSN: 2381-8654

Journal Of Internal Medicine \& Primary Healthcare | ISSN: 2574-2493

Journal Of Light \& Laser Current Trends

Journal Of Medicine Study \& Research | ISSN: 2639-5657

Journal Of Modern Chemical Sciences

Journal Of Nanotechnology Nanomedicine \& Nanobiotechnology | ISSN: 2381-2044

Journal Of Neonatology \& Clinical Pediatrics | ISSN: 2378-878X

Journal Of Nephrology \& Renal Therapy | ISSN: 2473-7313

Journal Of Non Invasive Vascular Investigation | ISSN: 2572-7400

Journal Of Nuclear Medicine Radiology \& Radiation Therapy | ISSN: 2572-7419

Journal Of Obesity \& Weight Loss | ISSN: 2473-7372

Journal Of Ophthalmology \& Clinical Research | ISSN: 2378-8887

Journal Of Orthopedic Research \& Physiotherapy | ISSN: 2381-2052

Journal Of Otolaryngology Head \& Neck Surgery | ISSN: 2573-010X

Journal Of Pathology Clinical \& Medical Research

Journal Of Pharmacology Pharmaceutics \& Pharmacovigilance | ISSN: 2639-5649

Journal Of Physical Medicine Rehabilitation \& Disabilities | ISSN: 2381-8670

Journal Of Plant Science Current Research | ISSN: 2639-3743

Journal Of Practical \& Professional Nursing | ISSN: 2639-5681

Journal Of Protein Research \& Bioinformatics

Journal Of Psychiatry Depression \& Anxiety | ISSN: 2573-0150

Journal Of Pulmonary Medicine \& Respiratory Research | ISSN: 2573-0177

Journal Of Reproductive Medicine Gynaecology \& Obstetrics | ISSN: 2574-2574

Journal Of Stem Cells Research Development \& Therapy | ISSN: 2381-2060

Journal Of Surgery Current Trends \& Innovations | ISSN: 2578-7284

Journal Of Toxicology Current Research | ISSN: 2639-3735

Journal Of Translational Science And Research

Journal Of Vaccines Research \& Vaccination | ISSN: 2573-0193

Journal Of Virology \& Antivirals

Sports Medicine And Injury Care Journal | ISSN: 2689-8829

Trends In Anatomy \& Physiology | ISSN: 2640-7752

Submit Your Manuscript: https://www.heraldopenaccess.us/submit-manuscript 